\title{
Effect of dietary sodium on airways responsiveness and its importance in the epidemiology of asthma: an evaluation in three areas of northern England
}

Graham Devereux, Jeremy R Beach, Carol Bromly, Alison J Avery, S M Taghi Ayatollahi, Susan M Williams, S Christopher Stenton, Stephen J Bourke, David J Hendrick

\begin{abstract}
Background - Although several investigations have shown a relationship between asthma (or its surrogate, airways responsiveness) and dietary or urinary sodium, others have not, and the matter remains controversial. This "salt effect" has been investigated during two recent epidemiological surveys of men in northern England. The first assessed the possible effect on airways responsiveness of occupational exposure to welding fumes, and the second characterised airways responsiveness in two geographically distinct residential areas. Thus, three separate study areas/populations were involved.
\end{abstract}

Methods - Investigation 1 involved 1059 shipyard workers aged 16-27 years who were exposed variously to welding fumes, and Investigation 2 involved 587 men aged 20-44 years who lived in rural West Cumbria or in urban Newcastle upon Tyne. In Investigation 1, a 24 hour urine specimen was requested from each subject with quantifiable airways responsiveness $\left(P_{20} \leqslant 6400 \mu g\right.$ methacholine) and from an equal number of subjects without measurable airways responsiveness from the same occupational subgroup. In Investigation 2 , every subject was asked to provide a 24 hour urine specimen.

Results - Of the men undergoing methacholine tests, satisfactory 24 hour urine specimens were obtained from $234(22 \cdot 1 \%)$ in Investigation 1 and 232 (39.5\%) in Investigation 2. Analysis using multiple linear regression, multiple linear logistic regression, and multiple regression for censored data produced consistent results within each study population but conflicting results between them, such that there was no hint of a relationship between airways responsiveness and 24 hour urinary sodium excretion in the shipyard workers of Investigation 1 nor in the rural West Cumbrian population of Investigation 2, but an association was found in the urban Newcastle population of Investigation 2 . All study populations were sufficiently large to demonstrate anticipated relationships between airways responsiveness and atopy, baseline $\mathrm{FEV}_{1}$, and (Newcastle only) age.
Conclusions - If airways responsiveness is related to dietary sodium the relationship is not likely to be strong.

(Thorax 1995;50:941-947)

Keywords: methacholine chloride, airways responsiveness, asthma, dietary sodium.

Studies from Africa and the Pacific suggest that there is something about a "westernised" way of life which increases the incidence and prevalence of asthma. ${ }^{1-3}$ The daily intake of sodium is well known to increase with economic development, and in 1985 Burney suggested that some of the excess prevalence of asthma in "westernised" societies may be a direct consequence of greater salt consumption. ${ }^{45}$ In the past decade a number of studies have investigated this hypothesis. Some have supported an association between sodium intake and asthma (or its surrogate, airways responsiveness), whilst others have failed to find such an association. The initial study described a correlation between regional table salt purchases and regional asthma mortality in men and children, but not in women. ${ }^{5}$ A subsequent epidemiological study of asthma prevalence in two Hampshire villages showed a strong and significant association between the response to inhaled histamine and the 24 hour excretion of sodium in men aged 18-64 years. ${ }^{6}$ Some of the investigators involved with this study have since reported the results of a larger study of men and women aged 18-70 years and were unable to find any association between airways responsiveness to methacholine and 24 hour sodium excretion. ${ }^{7}$ A study of military veterans aged 44-82 in the USA suggested an association between airways responsiveness to methacholine and excretion of potassium but not of sodium. ${ }^{8}$

In addition to these epidemiological studies, several interventional studies have reported the effect of manipulation of sodium intake on airways responsiveness. A small open study showed a significant increase in airways responsiveness to histamine in men and women when dietary salt intake was increased. ${ }^{9}$ A double blind crossover trial to assess the effect on airways responsiveness to histamine of placebo or slow-release sodium in asthmatic subjects established on a low sodium diet found an increase in airways responsiveness in those receiving sodium supplementation and 
a significant association between airways responsiveness and sodium excretion in men but not women. ${ }^{10} \mathrm{~A}$ more recent study of similar design was able to demonstrate, not only a significant increase in airways responsiveness to methacholine, but a fall in forced expiratory volume in one second $\left(\mathrm{FEV}_{1}\right)$ and a decrease in peak flow rate in those on sodium supplementation. ${ }^{11}$ A similar investigation (but with low power) was unable to demonstrate an effect on peak flow rate when dietary sodium intake was manipulated. ${ }^{12}$ Much of the evidence for an association is restricted to men. The evidence for an association between sodium excretion and asthma is thus conflicting, and the matter remains controversial.

At the time when some of these reports were being published, we were preparing two surveys of asthma and airways responsiveness in northern England - one in workers (largely men) at two shipyards in north-west England designed to investigate whether exposure to welding fumes could be implicated in causing occupational asthma, and the other in two general populations (men only) living further north on the north-west coast (rural West Cumbria) and the north-east coast (urban Newcastle upon Tyne) designed to assess any asthmagenic effect attributable to geographical site of residence. We felt that it was important to investigate the possible association between dietary sodium and airways responsiveness lest it confounded our results.

\section{Methods}

SUBJECTS

Investigation 1 was carried out during the summers of 1989 and 1990 at two shipyards belonging to Vickers Shipbuilding and Engineering, one in Barrow in Furness and one in Birkenhead. The study population comprised welders and caulker burners who had commenced apprenticeships in 1980-7 directly upon leaving school, together with parallel subgroups of workers from other shop floor trades and office jobs. These subjects were aged 19-27 years. There was also a group of school leavers aged 16-17 years who were potential recruits for apprenticeships during the two survey years, 1989 and 1990 . The study population could therefore be separated into three welding fume exposure subgroups - high, ambient, and negligible.

Investigation 2 was carried out between October 1992 and March 1993. It was based in West Cumbria on the west coast and in Newcastle upon Tyne on the east coast. All subjects were men aged 20-44 years who had been selected randomly from family practitioner registers. Subjects in both investigations underwent measurements of height and weight and completed a structured questionnaire. ${ }^{13}$ The investigations were approved by local ethical committees in Cumbria and Newcastle.

\section{SKIN PRICK TESTS}

In Investigation 1 Phazets (Pharmacia, Uppsala, Sweden) impregnated with the following solutions were used: cat, timothy grass, Dermatophagoides pteronyssinus, Cladosporium herbarum, histamine, and a negative saline control. In Investigation 2 ALK lancets (ALK, Hørsholm, Denmark) were used, together with ALK Soluprick allergen extract solutions of cat, timothy grass, Dermatophagoides pteronyssinus, Cladosporium herbarum, histamine, and saline. For both investigations the geometric mean of the maximum weal diameter and its maximum perpendicular diameter was calculated for each test. Atopic status was quantified by the number of allergen weals with a mean diameter of $4 \mathrm{~mm}$ or more greater than that of the saline control, in practice an integer from 0 to 4 . A diameter of $4 \mathrm{~mm}$ was chosen because it gave the greatest power for demonstrating the effects of atopy in regression analyses.

\section{SPIROMETRY}

Measurements of ventilatory function were made using a Screenmate pneumotachometer (Jaeger UK Ltd, Market Harborough, UK) with software by Collingwood Measurement Ltd (Packington, Leicestershire, UK). In addition, for Investigation 2 a P K Morgan rolling seal spirometer with PK Morgan software (Chatham, UK) was used in some subjects. Lung function equipment was calibrated twice daily and all values were corrected to BTPS.

\section{METHACHOLINE TESTS}

In both investigations airways responsiveness was quantified from methacholine tests using a locally developed dosimeter and protocol. ${ }^{14}$ Following measurement of baseline $\mathrm{FEV}_{1}$, sequential doubling cumulative doses of methacholine (dose range 3.125-6400 $\mu \mathrm{g}$ ) were inhaled at five minute intervals until a more than $20 \%$ decrement in $\mathrm{FEV}_{1}$ from baseline was attained (that is, a positive test), or the maximum dose of $6400 \mu \mathrm{g}$ had been administered. For a positive test the cumulative dose of methacholine provoking a $20 \%$ decrement in $\mathrm{FEV}_{1}\left(\mathrm{PD}_{20}\right)$ was computed by linear interpolation from a dose-response plot. In subjects with little or no evidence of asthmatic activity from history and baseline measurements of spirometric parameters, shortened protocols were used which have been shown to produce no distortion in computed $\mathrm{PD}_{20} \cdot{ }^{15}$ Solutions of methacholine used in the nebulisers of the dosimeter were changed at least twice daily or after a maximum of four tests so that any concentration of the solution due to evaporation did not materially affect the results. ${ }^{1617}$ Using this method a $\mathrm{PD}_{20}$ of $<200 \mu \mathrm{g}$ is almost always associated with active asthma, a $\mathrm{PD}_{20}$ of $200-1000 \mu \mathrm{g}$ is sometimes associated with active asthma, and a $\mathrm{PD}_{20}$ of $>1000 \mu \mathrm{g}$ is almost never associated with active asthma. ${ }^{18}$

COLLECTION OF 24 HOUR URINE SPECIMENS In Investigation 1 each subject with a positive methacholine test was requested to provide a 24 hour urine specimen, as was a paired subject from the same occupational subgroup whose 
methacholine test failed to produce a $20 \%$ decrement in $\mathrm{FEV}_{1}$. No account of the pairing was taken in the analysis. Each subject was asked to commence the 24 hour collection the morning after attending the survey centre and to return the collection the day after completion. In Investigation 2 all subjects were asked to participate, to empty their bladders at the time of the survey visit, and to complete the collection of urine 24 hours later. The specimens were returned at the earliest convenient opportunity.

In neither investigation were subjects informed of the ion of interest. They were all given a five litre container together with verbal and written instructions. For each 24 hour collection the volume was measured using a two litre measuring cylinder and a $20 \mathrm{ml}$ aliquot was frozen for later analysis. Sodium and potassium were measured on a Hitachi 717 multichannel analyser (Boehringer Mannheim, Lewes, UK) using sodium and potassium ion selective electrodes. Creatinine was measured on a Cobas Bio centrifugal analyser (Roche Diagnostics, Welwyn Garden City, UK) using a Jaffe rate reaction. All measurements for each investigation were made on the same day by a single member of the Biochemistry Department at Newcastle General Hospital who had no knowledge of the precise source of each specimen.

\section{STATISTICAL ANALYSES}

Analyses were performed using $\log _{10}$ transformed values of both $\mathrm{PD}_{20}$ (when this was quantifiable) and urinary constituents. Basic statistical analyses and linear regression analyses were performed using the STATA Release 3 statistical package (Computing Resource Center, Santa Monica, USA). Airways responsiveness is known to be influenced by several factors in addition to the possible effect of dietary sodium. To control for these covariates and to evaluate the possible independent effects of urinary constituents various forms of regression analyses were performed. Regression analyses related the log transformed $\mathrm{PD}_{20}$ values to atopic status, baseline $\mathrm{FEV}_{1}$, age, smok-

Table 1 Mean (95\% CI) 24 hour urinary volume and excretion of sodium, potassium and creatinine

\begin{tabular}{|c|c|c|c|c|}
\hline & \multirow{2}{*}{$\begin{array}{l}\text { Mean volume } \\
\text { ( } 95 \% \text { CI) } \\
\text { (l/24 hours) }\end{array}$} & \multicolumn{3}{|c|}{ Geometric mean ( $95 \% \mathrm{CI})$ (mmol/24 hours) } \\
\hline & & Sodium & Potassium & Creatinine \\
\hline \multicolumn{5}{|l|}{$\begin{array}{l}\text { Investigation } 1 \\
\text { (by welding fume exposure) }\end{array}$} \\
\hline High $(n=54)$ & & $\begin{array}{l}180 \\
(164 \text { to } 198)\end{array}$ & $\begin{array}{l}68 \cdot 5 \\
(60 \cdot 9 \text { to } 77 \cdot 1)\end{array}$ & $\begin{array}{l}14 \cdot 4 \\
(13 \cdot 3 \text { to } 15 \cdot 7)\end{array}$ \\
\hline Ambient $(n=121)$ & & 184 & $72 \cdot 1$ & $15 \cdot 6$ \\
\hline Negligible $(n=59)$ & & 187 & 71.8 & $15 \cdot 1$ \\
\hline Total $(n=234)$ & $\begin{array}{l}1.28^{*} \\
(1.22 \text { to } 1.34)\end{array}$ & $\begin{array}{l}184^{* *} \\
(176 \text { to } 193)\end{array}$ & $\begin{array}{l}71 \cdot 2 \\
(67 \cdot 6 \text { to } 74 \cdot 9)\end{array}$ & $\begin{array}{l}15 \cdot 2 \\
(14 \cdot 6 \text { to } 15 \cdot 7)\end{array}$ \\
\hline \multicolumn{5}{|l|}{$\begin{array}{l}\text { Investigation } 2 \\
\text { (by residence) }\end{array}$} \\
\hline & & $\begin{array}{l}169 \\
(158 \text { to } 182)\end{array}$ & $\begin{array}{l}73 \cdot 2 \\
(68 \cdot 0 \text { to } 78 \cdot 7)\end{array}$ & $\begin{array}{l}14 \cdot 5 \\
(13 \cdot 8 \text { to } 15 \cdot 1)\end{array}$ \\
\hline West Cumbria $(n=121)$ & & $\begin{array}{l}169 \\
(158 \text { to } 181)\end{array}$ & $\begin{array}{l}77 \cdot 6 \\
(72 \cdot 9 \text { to } 82 \cdot 7)\end{array}$ & $\begin{array}{l}14 \cdot 6 \\
(14 \cdot 1 \text { to } 15 \cdot 1)\end{array}$ \\
\hline Total $(n=232)$ & $\begin{array}{l}1 \cdot 58^{*} \\
(1.51 \text { to } 1.65)\end{array}$ & $\begin{array}{l}169^{* *} \\
(161 \text { to } 178)\end{array}$ & $\begin{array}{l}75 \cdot 5 \\
(72 \cdot 0 \text { to } 79 \cdot 1)\end{array}$ & $\begin{array}{l}14 \cdot 5 \\
(14 \cdot 1 \text { to } 14 \cdot 9)\end{array}$ \\
\hline
\end{tabular}

${ }^{*} \mathrm{p}<0.001 ;{ }^{* *} \mathrm{p}<0.02$. ing habit (never, ex, current), log (potassium), $\log$ (creatinine) and $\log$ (sodium). Regression of $\mathrm{PD}_{20}$ data is complicated by right censoring of $\mathrm{PD}_{20}$ values at the maximum measurable level of $6400 \mu \mathrm{g}$ (with our protocol), and so multiple linear regression analysis utilised only subjects with quantifiable airways responsiveness $\left(\mathrm{PD}_{20} \leqslant 6400 \mu \mathrm{g}\right) .{ }^{19}$ To utilise all the $\mathrm{PD}_{20}$ data we used two other multiple regression techniques: logistic regression which assessed the probability of obtaining a $\mathrm{PD}_{20}$ of $\leqslant 6400 \mu \mathrm{g}$, and regression analysis for censored data which used the log transformed values for $\mathrm{PD}_{20}$ and identified values of $>6400 \mu \mathrm{g}$ as right censored. $^{20}$ In Investigation 2 (but not Investigation 1) data were collected in such a way that airways responsiveness could be expressed by a dose-response slope, the log transformed value of which was also used in multiple regression analysis. $^{21}$

\section{Results}

A total of 1059 men from Investigation 1 underwent methacholine tests and $466(44.0 \%)$ had quantifiable levels of airways responsiveness $\left(\mathrm{PD}_{20} \leqslant 6400 \mu \mathrm{g}\right)$. Approximately 500 agreed to collect 24 hour urine specimens, but only $287(27 \cdot 1 \%$ of the 1059$)$ returned specimens to the survey centres. Of the specimens received, $53(18.5 \%)$ had either a volume of less than $500 \mathrm{ml}$ or a total creatinine less than $9 \mathrm{mmol} / 24$ hours (the lower defining limits for an acceptable 24 urine collection within the analysing laboratory) and so were excluded from the analysis as probably incomplete. Of the remaining 234 specimens, 139 (59.4\%) were from subjects with quantifiable airways responsiveness, and 95 from subjects without. Data were incomplete for one of these subjects who had refused skin prick tests.

A total of 587 men from Investigation 2 (285 in West Cumbria and 302 in Newcastle) underwent methacholine tests. At all levels of airways responsiveness there were no differences in prevalence between West Cumbria and Newcastle. Overall, quantifiable levels of airways responsiveness were noted in 79 men $(27.7 \%)$ in West Cumbria and 85 men $(28.2 \%)$ in Newcastle. A total of 262 men (44.6\%) returned urine specimens of which $232(88 \cdot 5 \%)$ were deemed acceptable; 121 were from West Cumbria and 111 were from Newcastle. Of the 232 men with acceptable collections 72 (31\%) had quantifiable levels of airways responsiveness - 39 in West Cumbria (32.2\%) and 33 in Newcastle $(29 \cdot 7 \%)$.

Table 1 shows the geometric mean and its $95 \%$ confidence interval for the urinary volume and excretion of sodium, potassium, and creatinine in the urine specimens which were considered to have been collected satisfactorily from both investigations. The mean volume of the collections was significantly greater in Investigation 2 , whilst sodium excretion was significantly greater in Investigation 1 . There were no significant differences between the three welding fume exposure subgroups of Investigation 1 , nor between the two residence subgroups of Investigation 2 . 
Table 2 Geometric mean (95\% CI) 24 hour urinary sodium excretion by level of airways responsiveness

\begin{tabular}{|c|c|c|c|}
\hline \multirow[t]{2}{*}{$P D_{20}(\mu g)$} & \multirow[t]{2}{*}{$n$} & \multicolumn{2}{|c|}{$\begin{array}{l}\text { Urinary sodium excretion } \\
\text { (mmol/24 hours) }\end{array}$} \\
\hline & & $\begin{array}{l}\text { Geometric } \\
\text { mean }\end{array}$ & $\begin{array}{l}95 \% \\
C I\end{array}$ \\
\hline \multicolumn{4}{|l|}{$\begin{array}{l}\text { Investigation } 1 \\
\text { (shipyards) }\end{array}$} \\
\hline $\begin{array}{l}\leqslant 200 \\
>200, \leqslant 1000 \\
>1000, \leqslant 6400 \\
>6400\end{array}$ & $\begin{array}{l}37 \\
42 \\
60 \\
95\end{array}$ & $\begin{array}{l}179 \\
177 \\
199 \\
181\end{array}$ & $\begin{array}{l}160 \text { to } 200 \\
156 \text { to } 201 \\
181 \text { to } 218 \\
169 \text { to } 193\end{array}$ \\
\hline \multicolumn{4}{|l|}{$\begin{array}{l}\text { Investigation } 2 \\
\text { (Newcastle) }\end{array}$} \\
\hline $\begin{array}{l}\leqslant 200 \\
>200, \leqslant 1000 \\
>1000, \leqslant 6400 \\
>6400\end{array}$ & $\begin{array}{r}7 \\
14 \\
12 \\
78\end{array}$ & $\begin{array}{l}200 \\
171 \\
175 \\
166\end{array}$ & $\begin{array}{l}133 \text { to } 300 \\
140 \text { to } 209 \\
150 \text { to } 204 \\
152 \text { to } 181\end{array}$ \\
\hline \multicolumn{4}{|l|}{$\begin{array}{l}\text { Investigation } 2 \\
\text { (West Cumbria) }\end{array}$} \\
\hline $\begin{array}{l}\leqslant 200 \\
>200, \leqslant 1000 \\
>1000, \leqslant 6400 \\
>6400\end{array}$ & $\begin{array}{l}12 \\
13 \\
14 \\
82\end{array}$ & $\begin{array}{l}169 \\
182 \\
179 \\
166\end{array}$ & $\begin{array}{l}140 \text { to } 204 \\
153 \text { to } 216 \\
162 \text { to } 196 \\
151 \text { to } 182\end{array}$ \\
\hline
\end{tabular}

In table 2 sodium excretion measurements are displayed according to the different levels of airways responsiveness: marked, $\mathrm{PD}_{20}$ $\leqslant 200 \mu \mathrm{g}$; moderate, $\mathrm{PD}_{20}>200, \leqslant 1000 \mu \mathrm{g}$; mild, $\mathrm{PD}_{20}>1000, \leqslant 6400 \mu \mathrm{g}$; unquantifiable, $\mathrm{PD}_{20}>6400 \mu \mathrm{g}$. For the shipyard workers of Investigation 1 and the West Cumbrian population of Investigation 2, no trend relating geometric mean sodium excretion to airways responsiveness is evident. By contrast, for the Newcastle population of Investigation 2 there is a suggestion of a gradient, with higher levels of airways responsiveness being associated with higher geometric mean sodium excretion. One way analysis of variance, however, indicated that this trend was not significant.

Multiple linear regression analyses for subjects with quantifiable levels of airways responsiveness (138 from the shipyards, 39 from West Cumbria, 33 from Newcastle) related log $\left(\mathrm{PD}_{20}\right)$ with urinary constituents after adjusting for the effects of atopy, baseline $\mathrm{FEV}_{1}$, current smoking status, and age. No significant association was found between airways re- sponsiveness and any of the urinary constituents, but low numbers limited the power of these analyses.

Linear logistic regression analysis included airways responsiveness data from all subjects. This technique related the probability of a subject having a $\mathrm{PD}_{20}$ of $\leqslant 6400 \mu \mathrm{g}$ to urinary constituents after adjusting for the effects of other covariates outlined above. Among the shipyard workers and the West Cumbrian population there was no significant association between airways responsiveness and any of the urinary constituents, nor was there any hint of this. Similar analysis from the Newcastle population suggested a positive association between the probability of a positive methacholine test and urinary sodium $(p<0.03)$, after taking account of the effects of atopy, baseline $\mathrm{FEV}_{1}$, age, and smoking. Altering the diagnostic cutoff for $\mathrm{PD}_{20}$ to $\leqslant 1000 \mu \mathrm{g}$ (the upper limit at which airways responsiveness may be associated with asthmatic symptoms ${ }^{14}$ ) made no difference to these outcomes.

Regression analysis for censored data utilised data from subjects with unquantifiable levels of airways responsiveness (censored at a $\mathrm{PD}_{20}$ of $>6400 \mu \mathrm{g}$ ), but it treated the quantifiable levels as a continuous rather than a categorical variable in order to compute maximum likelihood estimates of regression coefficients (table 3). Again, no association was found between airways responsiveness and urinary sodium in the shipyard or West Cumbrian populations, but an association was evident in the Newcastle population after taking account of the other variables of relevance.

In Investigation 2 it was possible to quantify airways responsiveness additionally by the dose-response slope. ${ }^{21}$ Multiple linear regression analyses related log (dose-response slope) to the urinary constituents after adjusting for the effects of atopy, baseline $\mathrm{FEV}_{1}$, current smoking status, and age. A significant positive association was again found between airways responsiveness and urinary sodium in the Newcastle population but not in the West Cumbrian population (table 4).

Table 3 Regression analysis for censored data: $\log _{10}\left(P D_{20}\right)$ against covariates

\begin{tabular}{|c|c|c|c|}
\hline & \multicolumn{3}{|c|}{$\begin{array}{l}\text { Estimates of regression coefficients } \\
(95 \% \text { confidence interval })\end{array}$} \\
\hline & \multirow{2}{*}{$\begin{array}{l}\text { Investigation } 1 \\
\text { Shipyards }\end{array}$} & \multicolumn{2}{|l|}{ Investigation 2} \\
\hline & & Newcastle & West Cumbria \\
\hline Atopy (per positive allergen) & $\begin{array}{l}-0.714 \\
(-0.897 \text { to }-0.531) \\
p<0.001\end{array}$ & \multirow{7}{*}{$\begin{array}{l}-0.800 \\
(-1.252 \text { to }-0.348) \\
\text { p<0.002 } \\
0.638 \\
(0.115 \text { to } 1.162) \\
\mathrm{p}<0.02 \\
0.058 \\
(0.002 \text { to } 0.115) \\
\mathrm{p}<0.05 \\
-0.256 \\
(-1.077 \text { to } 0.565) \\
-3.319 \\
(-6.262 \text { to }-0.375) \\
\mathrm{p}<0.03 \\
2.387 \\
(-2.208 \text { to } 6.983) \\
1.265 \\
(-1.342 \text { to } 3.872)\end{array}$} & $\begin{array}{l}-1.039 \\
(-1.444 \text { to }-0.634) \\
p<0.001\end{array}$ \\
\hline Baseline $\mathrm{FEV}_{1}$ (per litre) & $\begin{array}{l}0.495 \\
(0.318 \text { to } 0.672) \\
p<0.001\end{array}$ & & $\begin{array}{l}0.871 \\
(0.289 \text { to } 1.453) \\
\mathrm{p}<0.005\end{array}$ \\
\hline Age (per year) & $\begin{array}{l}0.001 \\
(-0.045 \text { to } 0.047)\end{array}$ & & $\begin{array}{l}0.027 \\
(-0.025 \text { to } 0.079)\end{array}$ \\
\hline Current smokers $v$ current non-smokers & $\begin{array}{l}-0.124 \\
(-0.459 \text { to } 0.210)\end{array}$ & & $\begin{array}{l}-0.593 \\
(-1.462 \text { to } 0.275)\end{array}$ \\
\hline Log(sodium) (per log mmol/24 hours) & $\begin{array}{l}0.245 \\
(-0.742 \text { to } 1.233)\end{array}$ & & $\frac{-1.352}{(-4.299}$ to 1.594$)$ \\
\hline Log(creatinine) (per log mmol/24 hours) & $\begin{array}{l}-0.730 \\
(-2.154 \text { to } 0.695)\end{array}$ & & $\begin{array}{l}1.448 \\
(-4.343 \text { to } 7 \cdot 239)\end{array}$ \\
\hline $\log$ (potassium) (per log mmol/24 hours) & $\begin{array}{l}-0.230 \\
(-1.219 \text { to } 0.759)\end{array}$ & & $\begin{array}{l}0.047 \\
(-3.183 \text { to } 3.278)\end{array}$ \\
\hline Constant & $2 \cdot 732$ & $-4 \cdot 536$ & $-2 \cdot 595$ \\
\hline
\end{tabular}


Table 4 Multiple linear regression analysis (Investigation 2): airway responsiveness expressed as $\log _{10}$ (dose-response slope) against covariates

\begin{tabular}{|c|c|c|}
\hline & \multicolumn{2}{|c|}{$\begin{array}{l}\text { Estimates of regression coefficients } \\
\text { ( } 95 \% \text { confidence intervals) }\end{array}$} \\
\hline & Nerwcastle & West Cumbria \\
\hline Atopy (per positive allergen) & $\begin{array}{l}0.475 \\
(0.259 \text { to } 0.690) \\
\mathrm{p}<0.001 \\
-0.215 \\
(-0.430 \text { to } 0.002)\end{array}$ & $\begin{array}{l}0.683 \\
(0.481 \text { to } 0.884) \\
p<0.001 \\
-0.344 \\
(-0.614 \text { to }-0.075) \\
p<0.02\end{array}$ \\
\hline Age (per year) & $\begin{array}{l}-0.025 \\
(-0.050 \text { to } 0.001)\end{array}$ & $\begin{array}{l}-0.015 \\
(-0.039 \text { to } 0.009)\end{array}$ \\
\hline Current smokers $v$ current non-smokers & $\begin{array}{l}0.094 \\
(-0.290 \text { to } 0.477)\end{array}$ & $\begin{array}{l}0.265 \\
(-0.147 \text { to } 0.676)\end{array}$ \\
\hline Log(sodium) (per log mmol/24 hours) & $\begin{array}{l}1.765 \\
(0.502 \text { to } 3.028) \\
\mathrm{p}<0.01\end{array}$ & $\begin{array}{l}0.448 \\
(-0.681 \text { to } 1.577)\end{array}$ \\
\hline $\log$ (creatinine) (per log mmol/24 hours) & $\begin{array}{l}-1.463 \\
(-3.448 \text { to } 0.522)\end{array}$ & $\begin{array}{l}-0.635 \\
(-3.143 \text { to } 1.872)\end{array}$ \\
\hline $\log$ (potassium) (per $\log \mathrm{mmol} / 24$ hours) & $\begin{array}{l}-0.641 \\
(-1.869 \text { to } 0.587)\end{array}$ & $\begin{array}{l}-0 \cdot 172 \\
(-1 \cdot 626 \text { to } 1 \cdot 281)\end{array}$ \\
\hline Constant & $2 \cdot 487$ & $1 \cdot 269$ \\
\hline
\end{tabular}

Significance of coefficients $>0.05$ unless specified.

Further analysis of data included additional terms for trade and hence welding fume exposure (Investigation 1) and place of residence (Investigation 2). This allowed for the primary aims of these investigations, but it did not alter the outcome with respect to sodium excretion.

\section{Discussion}

Whether or not airways responsiveness (and hence asthma) is related to dietary sodium is a matter of continuing controversy, and so it is not entirely surprising that the results of our evaluations proved to be conflicting. The three datasets were, however, obtained by essentially the same investigating team using the same equipment and methodology, and each showed much internal consistency. The wide range over which $\mathrm{PD}_{20}$ could be quantified provided particular analytical power, as did the precision of the $\mathrm{PD}_{20}$ measurements. ${ }^{14}$ None of the datasets can consequently be discarded lightly, especially as each demonstrated a number of relationships with airways responsiveness which have been documented previously.

In fact, the larger populations from which the participants with satisfactory 24 hour urinary collections were drawn all showed that $\mathrm{PD}_{20}$ was related negatively to atopy and current smoking and positively to baseline $\mathrm{FEV}_{1}$ and age. ${ }^{22-26}$ Within the shipyard population $\mathrm{PD}_{20}$ was also found to be related negatively to welding fume exposure. When the study populations were reduced in number to evaluate relationships with the urinary constituents, the relationship of airways responsiveness to current smoking was lost in all three study populations, the relationship to age was lost in the West Cumbrian and shipyard populations, and the relationship to welding fumes was lost in the shipyard population. Thus, our failure to demonstrate a relationship between airways responsiveness and urinary sodium in the shipyard and West Cumbrian populations may have been a consequence, at least in part, of inadequate numbers. If this was the case and airways responsiveness is truly related to dietary sodium, our findings imply that the relationship is less strong than those relating airways responsiveness to atopy or baseline $\mathrm{FEV}_{1}$.

Inadequate numbers within the study population is not, however, a fully sufficient explanation for our findings, since the shipyard population was twice the size of the Newcastle population and the size of all three study populations was similar to or greater than that in which the relationship was first observed. ${ }^{6}$ Our study populations were considerably smaller than the "normal population" of 1702 studied recently by Britton and colleagues who found, nevertheless, no evidence linking airways responsiveness to dietary salt. ${ }^{7}$ Their investigation has consequently posed a major challenge to the hypothesis that dietary salt might influence asthma, especially as two of the authors contributed to the initial investigation which gave it birth. Only $50 \%$ of their subjects were men, however, and their ages ranged from 18 to 70 years. Many of those with airways obstruction, and hence with quantified values for $\mathrm{PD}_{20}$, are therefore likely to have had chronic obstructive pulmonary disease (COPD) rather than asthma (49\% of the 1702 had smoked).

Our own study populations were much younger and so were much less likely to be affected in this way, but in our investigations the distribution of sodium excretion was "censored" at the lower end by laboratory requirements that acceptable 24 hour specimens had volumes of at least $500 \mathrm{ml}$ and creatinine contents of at least $9 \mathrm{mmol}$. Britton and colleagues accepted all the returned specimens of urine, and a creatinine content as low as $6.9 \mathrm{mmol}$ was within the $95 \%$ range of the geometric mean. Unless the values of urinary sodium and airways responsiveness are both widely distributed there may be some difficulty in demonstrating a relationship between them. This factor may also have been relevant to the study of Britton and colleagues because $\mathrm{PD}_{20}$ values were obtained over a less wide range than in our investigations, and hence for only $11.8 \%$ of the 1702 subjects. Thus our investigations were possibly handicapped by small numbers and by a limited distribution of urinary sodium values, while the investigation of Britton and colleagues was possibly handicapped by the inclusion of urine samples collected over less than 24 hours and by a limited distribution of $\mathrm{PD}_{20}$ values, some of which may have reflected COPD rather than asthma.

These possible handicaps are, however, of limited importance, and it is surprising that no hint of a relationship between airways responsiveness and urinary sodium was found by Britton and colleagues or by ourselves in our shipyard and West Cumbrian populations, if indeed the relationship is a real one. An alternative explanation for our findings is that airways responsiveness is not related to dietary sodium and that our observations among the Newcastle population were spurious. Although this appears less plausible in view of the strength of existing published evidence, it is conceivable that a publication bias may have occurred in favour of positive observations. We con- 
sequently looked more closely at our Newcastle population in order to assess the possibility of selection bias or confounding.

The Newcastle population, but not the West Cumbrian population, showed a skewed distribution of social class, with over-representation of social classes I and II and underrepresentation of social class III. The participants from social classes I and II were also more likely to provide urine specimens. These biases may have been important because mean sodium excretion for social classes I and II appeared to be greater in Newcastle than in West Cumbria. Regression analyses did not, however, show any relation between social class and $\mathrm{PD}_{20}$, provided due account was taken of smoking. Poor participation rates in providing urine specimens may have introduced a further bias, but the actual effects of this are not easily assessed. It is likely that those living at the greatest distances from the survey centres and those without ready transport would have participated least.

Because relationships had been demonstrated linking $\mathrm{PD}_{20}$ with atopy, baseline $\mathrm{FEV}_{1}$, age, and smoking, we sought relationships between urinary sodium and each of these covariates. Although there was a hint that sodium excretion diminished with age, the only significant finding was a greater mean sodium excretion among current smokers compared with current non-smokers among the Newcastle, but not the West Cumbrian nor shipyard, populations. This too may have been important, especially as there were more current smokers in Newcastle than in West Cumbria. The inclusion of current smoking in the regression analyses ahead of urinary sodium did not, however, eliminate the significant relationship between $\mathrm{PD}_{20}$ and urinary sodium levels.

We cannot therefore prove that this relationship was spurious, but we suspect that this was so. There were no associations between sodium excretion and asthmatic symptoms, nor between sodium excretion and diagnosed asthma; and there is no clear biological mechanism for dietary or urinary sodium levels to influence asthma, nor for this to be manifested chiefly in men. We think the relationship demonstrated within our Newcastle population was largely attributable to chance, and it may be that the regression analyses did not allow fully for all the chance associations within the Newcastle population. There were, for example, more dog keepers in Newcastle and more gas cookers, and both (like smoking) were associated with higher levels of sodium excretion in Newcastle than in West Cumbria. The potential for confounding was least among the shipyard population where age was limited within a narrow range and social class confined almost entirely to social class III. Our observation that this study population (which was the largest of the three and showed the greatest prevalence of positive methacholine tests) failed to show any hint of a relationship between airways responsiveness and urinary sodium is possibly the most pertinent. It was among this population, however, where urine collections were least satisfactory, and where methacholine tests and urine collections were not concurrent. Whether an interval of hours (or at most a day or so) between the latter would have exerted any influence is unclear.

The hypothesis that dietary sodium is relevant to asthma arose initially because regional sales of table salt appeared to be related to local statistics of asthma mortality. There is reason to implicate dietary sodium in cardiovascular death, but death from asthma is rare and agents of aetiological relevance are not likely to be recognised from investigations of mortality unless they are particularly important or potent. Neither seems to be true for dietary sodium, and so the hypothesis may not be well founded - especially in view of emerging evidence that asthma death certification may be very unreliable in subjects aged $50-60$ years or more (the age range in which approximately $50 \%$ of asthma deaths are recorded). ${ }^{2728}$

It is evident that there are complex issues which complicate the investigation of a "salt effect" on airways responsiveness, and that the current controversy over the possible relationship will not be readily resolved. Although a definite influence of dietary sodium on airways responsiveness is a matter of importance and interest of itself, we were more concerned when planning these investigations by the possibility that differences in sodium balance across study subgroups might exert a confounding effect and hence obscure or exaggerate the possible effects of primary interest. Sodium excretion data might consequently be necessary in order to allow for this "salt effect". In the event, the values of urinary excretion of sodium were distributed evenly among the various study subgroups of each investigation, and the principal outcomes were not influenced by the results of the urinary analyses.

1 Godfrey RC. Asthma and IgE levels in rural and urban communities of The Gambia. Clin Allergy 1975;5:201-7.

2 Van Niekerk CH, Weinberg EG, Shore SC, De V Heese H, Van Schalkwyk DJ. Prevalence of asthma: a comparative study of urban and rural Xhosa children. Clin Allergy 1979;9:319-24.

3 Waite DA, Eyles EF, Tonkin SL, O'Donnell. Asthma prevalence in Tokelauan children in two environments. Clin Allergy 1980;10:71-5.

4 Gliebermann L. Blood pressure and dietary salt in human populations. Ecol Food Nutr 1973;2:143-56.

5 Burney PGJ. The causes of asthma - does salt potentiate bronchial reactivity? Discussion paper. $f R$ Soc Med 1987; 80:364-7.

6 Burney PGJ, Britton JR, Chinn S, Tattersfield AE, Platt HS, Papacosta AO, Kelson MC. Response to inhaled histamine and 24 hour sodium excretion. $B M F$ 1986;292 1483-6.

7 Britton JR, Pavord I, Richards K, Knox A, Wisniewski A Weiss $S$, Tattersfield AE. Dietary sodium intake and the risk of airway hyperreactivity in a random adult population. Thorax 1994;49:875-80.

8 Sparrow D, O'Connor GT, Rosner B, Weiss ST. Methacholine airway responsiveness and 24 hour urine excretion of sodium and potassium. Am Rev Respir Dis 1991; 144:722-5.

9 Javaid A, Cushley MJ, Bone MF. Effect of dietary salt on bronchial reactivity to histamine in asthma. $B M \mathcal{F} 1988$; 297:454.

10 Burney PGJ, Neild JE, Twort CHC, Chinn S, Jones TD, Mitchell WD, et al. Effect of changing dietary sodium on Mitchell WD, et al. Effect of changing dietary sodium on
the airway response to histamine. Thorax 1989;44:36-41. 11 Carey OJ, Locke C, Cookson JB. Effect of alterations of Carey OJ, Locke C, Cookson JB. Effect of alterations of
dietary sodium on severity of asthma in men. Thorax 1993; dietary sodiun

12 Lieberman D, Heimer D. Effect of dietary sodium on the severity of bronchial asthma. Thorax 1992;47:360-3

13 Hendrick DJ, Beach JR, Avery AJ, Dennis JH, Bromly CL Ward RJ, et al. An epidemiological investigation of asthma 
in apprentice (shipyard) welders. Report to the Medical Research Council and the Health \& Safety Executive, 1994.

14 Beach JR, Young CL, Avery AJ, Stenton SC, Dennis JH, Walters $\mathrm{EH}$, et al. Measurement of airway responsiveness to methacholine: relative importance of the precision of drug delivery and method of assessing response. Thorax 1993;48:239-43.

15 Hendrick DJ, Fabbri LM, Hughes JM, Banks DE, Barkman HW, Connolly MJ, et al Modification of the methacholine inhalation test and its epidemiologic use in polyurethan workers. Am Rev Respir Dis 1986;133:600-4.

16 Dennis JH, Stenton SC, Beach JR, Avery AJ, Walters EH, Hendrick DJ. Jet and ultrasonic nebuliser output: use of a new method for direct measurement of aerosol output. a new method for direct

17 Cockcroft DW, Hurst TS, Gore BP. Importance of evaporative losses during standardised nebulized inhalation provocation tests. Chest 1989;96:505-8.

18 Stenton SC, Beach JR, Avery AJ, Hendrick DJ. The value of questionnaires and spirometry in asthma surveillance programmes in the workplace. Occup Med 1993;4

19 Rijcken B, Schouten JP. Measuring bronchial responsiveness in epidemiology. Eur Respir $\mathcal{7} 1993 ; 6: 617-8$.

20 Amemiya $T$. Regression analysis when the dependent variable is truncated normal. Econometrica 1973;41:997-1016.

21 O'Connor G, Sparrow D, Taylor D, Segal M, Weiss S.
Analysis of dose-response curves to methacholine. An approach suitable to population studies. Am Rev Respir Dis $1987 ; 136: 1412-7$.

22 Burney PGJ, Britton JR, Chinn S, Tattersfield AE, Papacoasta AO, Kelson MC, et al. Descriptive epidemiology of bronchial reactivity in an adult population: results from a community study. Thorax $1987 ; 42: 38-44$.

23 Britton J, Pavord I, Richards K, Knox A, Wisniewski A Wahedna $\mathrm{I}$, et al. Factors influencing the occurrence of airway hyperreactivity in the general population: the importance of atopy and airway calibre. Eur Respir $\mathcal{F} 1994$; 7:881-7.

24 Bakke PS, Baste V, Gulsvik A. Bronchial responsiveness in a Norwegian community. Am Rev Respir Dis 1991;143: 317-22.

25 Gerrard JW, Cockcroft DW, Mink JT, Cotton DJ, Poonawala $R$, Dosman JA. Increased nonspecific bronchial reactivity in cigarette smokers with normal lung function. Am Rev Respir Dis 1989;122:577-81.

26 O'Connor G, Sparrow D, Segal MR, Weiss ST. Smoking, atopy, and methacholine airway responsiveness among middle-aged and elderly men. Am Rev Respir Dis 1989, 140:1520-6.

27 British Thoracic Association. Accuracy of death certificates in bronchial asthma. Thorax 1984;39:505-9.

28 Berrill WT Is the number of asthma deaths exaggerated? An audit from West Cumbria. BMF 1993;306:193-4. 